\title{
Construcción de una pedagogía decolonial ...una urgente acción humana
}

\author{
Rosa Cecilia Bustos Erazo ${ }^{1}$ \\ I.E.M. Nuestra Señora de Guadalupe, Colombia
}

Recepción: 14/03/2020

Evaluación: 18/03/2020

Aprobación: 01/04/2020

Artículo de Investigación-Reflexión

DOI: https://doi.org/10.22267/rhec.202424.71

\section{Resumen}

Este artículo presenta los resultados de un proceso investigativo con el objetivo de analizar tres lineamientos básicos para la construcción de una pedagogía decolonial: el primero, Reconocimiento de lo nuestro, reflexiona sobre la relación recíproca del hombre con la naturaleza, que se gesta desde las herencias culturales y los saberes actuales bajo una visión de endogénesis como la capacidad de habitar de forma coherente un territorio geográfico-cultural y generar pensamiento propio.

El segundo lineamiento: Interculturalidad crítica, proyecto epistémico, social y educativo, entendido como la dimensión ontológica del respeto por el otro y la diferencia, que legitima la alteridad como herramienta pedagógica, con perspectiva crítica, para desmontar el papel de la escuela como reproductora de formas del poder, del saber y del ser, propias de la colonialidad.

El tercer lineamiento: Pedagogía crítica, como práctica democrática, que se inscribe en un proceso reflexivo, con epistemología, didáctica y pedagogía caracterizada por la dialogicidad, la criticidad y la otredad, con potencialidad hermenéutica de transformación, liberación simbólica y epistémica hacia una praxis decolonizadora.

La pedagogía decolonial, propia de autodeterminación y autoliberación, enmarcada en los tres lineamientos, genera pensamiento

1 Rectora de la Institución Educativa Municipal Nuestra Señora de Guadalupe, Colombia. Magister en educación. Grupo de investigación GIDEP. Línea de investigación: pedagogía y currículo. Correo electrónico: ceciliabustos22@gmail.com. 각tps:// orcid.org/0000-0003-4492-0370 
decolonial, crítico, conducente a un proceso de resistencia e insurgencia que visibiliza la geopolítica del saber y la topología del ser, para que la escuela deje de ser espacio de colonización mental y se convierta en generadora de conocimiento emancipador.

Palabras clave: interculturalidad crítica; pedagogía decolonial; pedagogía crítica; pensamiento propio.

\title{
Construction of a decolonial pedagogy...an urgent human action
}

\begin{abstract}
This article showcases the research results of the analysis of three basic guidelines for the construction of a decolonial pedagogy: The first one: Recognition of what is ours, this guideline reflects on the reciprocal relationship of man with nature, which is developed from cultural heritages and current knowledge under a vision of endogenesis as the ability to inhabit a geographical-cultural territory in a coherent way, generating its own way of thinking.

The second guideline: Critical interculturality, or the epistemic, social and educational project, understood as the ontological dimension of respect for the other and difference, which legitimizes otherness as a pedagogical tool, with a critical perspective, dismantling the role of the school as a reproducer of forms of power, knowledge and being, typical of the colonial era.

The third guideline: Critical Pedagogy, as a democratic practice, it is inscribed in a reflexive process, with epistemology, didactics and pedagogy characterized by dialogicity, criticality and otherness, with a hermeneutic potential for transformation, symbolic and epistemic liberation towards a decolonizing praxis.

The decolonial pedagogy, proper to self-determination and selfliberation framed in the three guidelines, generates decolonial, critical thinking, leading to a process of resistance and insurgency that makes visible the geopolitics of knowledge and the topology of being, so that the school ceases to be a space of mental colonization and becomes a generator of emancipatory knowledge.
\end{abstract}


Key words: critical interculturality; decolonial pedagogy; critical pedagogy; personal thinking.

\section{A construção de uma pedagogia descolonial ... uma ação humana urgente}

\section{Resumo}

Este artigo apresenta os resultados de um processo investigativo com o objetivo de analisar três diretrizes básicas para a construção de uma pedagogia descolonial: A primeira: o reconhecimento do que é nosso, reflete na relação recíproca do homem com a natureza, que é gestada a partir de heranças culturais e conhecimentos atuais sob uma visão de endogênese como a capacidade de habitar coerentemente um território geográficocultural, gerando o próprio pensamento.

A segunda diretriz: interculturalidade crítica, projeto epistêmico, social e educacional, entendida como a dimensão ontológica do respeito ao outro e à diferença, que legitima a alteridade como ferramenta pedagógica, com uma perspectiva crítica, desmontando o papel da escola como reprodutora de formas do poder, do saber e do ser, típico da colonialidade.

A terceira diretriz: A pedagogia crítica, como prática democrática, faz parte de um processo reflexivo, com epistemologia, didática e pedagogia caracterizadas pela dialogicidade, criticidade e alteridade, com potencial hermenêutico de transformação, libertação simbólica e epistêmica para uma práxis descolonizadora.

A pedagogia descolonial, típica da autodeterminação e da autoliberação enquadrada nas três diretrizes, gera um pensamento descolonial, crítico, propício a um processo de resistência e insurgência que torna visível a geopolítica do conhecimento e a topologia do ser, para que a escola saia de espaço de colonização mental e se torne em gerador de saberes emancipatórios.

Palavras-chave: interculturalidade crítica; pedagogia descolonial; pedagogia crítica; pensamento próprio. 


\section{Introducción}

"Leer críticamente el mundo es un nacer político-pedagógico; es decir, de la acción política que involucra la organización de grupos y de clases para intervenir en la reinvención de la sociedad."

Freire

"Nuestra historia es la historia de la búsqueda de identidad, de un ideal por presentarnos desde nosotros mismos y de la construcción de una imagen que dé cuenta de una mismidad llamada América

Latina."

Catalina León P.

Este artículo parte de la necesidad de leer el mundo críticamente, intervenir en la reinvención de la sociedad y avivar la llama de la decolonización, como acertadamente lo pensaron y escribieron el martinico Frantz Fanon y el brasileño Paulo Freire, cuando reconocen como una urgente acción humana el hecho de plantear y analizar los lineamientos educativos que contribuyen a la construcción de una "pedagogía decolonial, entendida como una reflexión crítica hacia los agenciamientos colectivos", ${ }^{2}$ productos de la colonialidad, que se instaura como el lado oscuro de la modernidad, ya que, a partir de la segunda mitad del siglo XVIII, Europa comenzó una nueva etapa de su historia, signada por profundas transformaciones en todos los órdenes de la vida social, política, económica, cultural y educativa, que tiene como acontecimiento más importante la disolución del feudalismo y la consolidación del capitalismo; también, el poder económico de la burguesía le otorgó poder político, lo que posibilitó el surgimiento de nuevas instituciones, paradigmas y concepciones que develaron un mundo más "moderno." Con la modernidad surgió un discurso, una narrativa que se difundió y se universalizó. En estas condiciones, Europa pasó a ser el centro del mundo capitalista: "El capitalismo mundial fue, desde su partida, colonial - moderno y eurocentrado". ${ }^{3}$

2 Aquileana. Gilles Deleuze: “Agenciamiento colectivo y Rizomas”, https://aquileana. wordpress.com/2011/12/02/ gilles-deleuze-agenciamiento-colectivo-y-rizomas/ (último acceso: 10 de agosto de 2018).

3 Aníbal Quijano, Colonialidad del poder, eurocentrismo y América Latina (Bogotá: Editorial Nueva América, 1998), 208 
Aquí la modernidad, no fue tan solo un fenómeno intraeuropeo en su construcción y consolidación; mucho tuvieron que ver otros pueblos de la "periferia"; el descubrimiento de América jugó un verdadero papel revolucionario en el proceso de modernización de Europa, por ello se puede afirmar que la Modernidad tiene su punto de origen en la conquista, con el establecimiento de un orden jerárquico que sitúa al hombre - europeo en la cúspide del ser, saber y poder:

El imaginario del mundo moderno/colonial surgió de la compleja articulación de fuerzas, de voces oídas o apagadas, de memorias compactas o fracturadas, de historias contadas desde un solo lado que suprimieron otras memorias y de historias que se contaron y cuentan desde la doble conciencia que genera la diferencia colonial y continúa diciendo "América es la otra cara" negada de la modernidad, es ese otro rostro encubierto, es ese cuerpo continental americano sacrificado, y subvalorado, sobre el cual se tendió un velo para cubrir su majestuosidad y grandeza. Este es el papel que los saberes sociales modernos tienen, es decir, descubrir la otra "cara oculta" del mundo periférico colonial. ${ }^{4}$

Es una modernidad que implementa racismos solapados, exclusión y marginación, como estrategias de continua manipulación y pensamiento hegemónico que aún tienen vigencia y actualidad, aparatos de control y vigilancia, reorganizados bajo el orden de los discursos y las semióticas de poder que homogenizan el pensamiento, para fortalecer lo único e idéntico, negar y anular la diferencia, que:

(...) Solo implica lo negativo y simplemente se deja llevar hasta la contradicción, en la medida en que se continúa subordinándola a lo idéntico; entonces, el primado de la identidad, como esta sea concebida, define el mundo de la representación, pero el pensamiento moderno nace del fracaso de la representación, como de la pérdida de las identidades y del descubrimiento de todas las fuerzas que actúan bajo la representación de lo idéntico; así, pues, todas las identidades no son más que simuladas, producidas como un efecto óptico, por un juego más profundo, que es el de la diferencia y la repetición.

De esta manera, la pedagogía moderna no puede reconocer ni visibilizar las diferencias entre los seres humanos, por cuanto su intención formativa es homogeneizar y estandarizar; de ahí que fuese una pedagogía colonizadora; es claro que se necesita formar un pensamiento autónomo, plural, crítico,

${ }^{4}$ Enríque Dussel, Europa, modernidad y eurocentrismo (Buenos Aires: Clacso, 1993), 63. 
que reconozca la diferencia y que contrarrestase el pensamiento hegemónico propio de la colonialidad y la manera de lograrlo es a través de la educación y de su base ideológica, que es la pedagogía y en especial la pedagogía decolonial, propia de la auto-determinación y la auto-liberación, y que la asumiera desde una mirada praxiológica.

Desde una perspectiva analítica, se plantea la construcción de una pedagogía decolonial, que se logra a partir del entrelazamiento de lineamientos educativos básicos, que estructuran una configuración triádica: el reconocimiento de lo nuestro, capaz de generar pensamiento propio; la interculturalidad crítica y la pedagogía crítica; la sinergia de estos tres lineamientos genera una pedagogía decolonial para que la escuela dejase de ser un espacio de colonización mental y entender que la decolonialidad de la educación se logra en la misma medida en que se reconoce la validez e importancia de los saberes "otros", no oficializados por la colonialidad.

\section{Urgencia de la construcción de una pedagogía decolonial}

Antes de tratar los tres lineamientos que se plantean para la construcción de una pedagogía decolonial, es necesario partir de la configuración epistémica de la pedagogía y las tendencias que han proliferado en la Historia de la educación y así poder argumentar la urgencia de una pedagogía decolonial.

Como se habla de una "pedagogía" decolonial, es muy importante argumentar sobre la configuración epistémica del término "pedagogía", al tener en cuenta las principales tendencias que han existido en la Historia de la educación. Se identifican cinco tendencias u orientaciones epistemológicas: la pedagogía como ciencia de la educación, como una de las ciencias de la educación, como saber pedagógico, como arte de enseñar (didáctica), y la pedagogía como reflexión de la educación. Sin embargo, sigue y seguirá vigente el controversial debate sobre la pedagogía y las ciencias de la educación; por lo tanto, no existe hasta ahora un consenso en la comunidad académica internacional sobre la configuración epistémica de la pedagogía.

Para tratar y situar nuestra temática, cabe anotar que "en Colombia la pedagogía es un saber pedagógico o una reflexión sobre la educación $\mathrm{y}$, además, la pedagogía no debe ser considerada un campo, sino una 
configuración conceptual comprensiva". ${ }^{5}$ Sin embargo, en Latinoamérica, y en especial en Colombia, a lo largo de la Historia de la educación la pedagogía ha sido considerada erradamente como un "objeto" y no como una "configuración conceptual comprensiva", ya que obedece a las diferentes imposiciones de los modelos pedagógicos extranjeros (de Europa, de Estados Unidos, etc.) que evidencian "la colonialidad del saber" y, por supuesto, su dominación, un objeto que se mueve y se desgasta con la subordinación y dominación de un pensamiento extranjero, hegemónico, que logra la dominación de los pueblos, para llevarlos a la marginalidad y la exclusión, porque no les permiten pensar, solamente doblegarse.

Así, la Historia de la educación colombiana es una copia de modelos educativos que no corresponden a la realidad, ni al devenir histórico del país; estos modelos, impuestos sin análisis crítico, sin descubrir ni siquiera la filosofía que los sustenta, se convirtieron en modelos hegemónicos $\mathrm{y}$, por lo tanto, se ha caminado siguiendo las huellas de otras culturas $\mathrm{y}$, tal como lo expuso el Nobel mexicano, Octavio Paz: "Hemos sido una idea extranjera, Europea y gringa"; en consecuencia, la pedagogía, los planes de estudio, los currículos, la evaluación, etc., que Colombia implementó y sigue implementando, obedecen a imposiciones extranjeras.

Colombia tuvo, en el siglo XX, tres momentos o etapas en su proceso educativo; así, en la primera mitad del siglo XX, recibió una total influencia europea y el modelo educativo que signó la época fue la Escuela Activa, caracterizada por una pedagogía inclinada a la formación de un hombre productivo, trabajador, práctico y útil (no pensante); a partir de la década del 50, la inversión de capital norteamericano exigió cambiar la educación latinoamericana e impuso el modelo educativo de la Tecnología Educativa, que obedece a una concepción de pedagogía eficientista industrial de la sociedad capitalista, a través de la teoría tayloriana y cifrada por el conductismo; al final del siglo XX y comienzos del XXI, el fenómeno de la globalidad fue absorbente y determinante; por lo tanto, la tercera etapa o modelo educativo corresponde a la globalización que, de manera absoluta, negó el sentido de lo nacional, arrebató "lo nuestro", la tradición y, lo que es más grave, arrebató nuestra identidad.

5 Alexander Ortiz Ocaña, "Configuración epistémica de la pedagogía. Tendencias que han proliferado en la historia de la educación", Revista de Historia de la Educación Latinoamericana, vol. 19, No. 29 (2017): 165-195. 
Este rápido recorrido histórico muestra que no fuimos capaces de construir un modelo pedagógico propio y menos una pedagogía propia, razón por la cual la pedagogía debe seguir siendo una ciencia autónoma, una teoría reflexiva del sistema educativo, con el fin de proteger al símbolo que torna reconocible: qué pertenece al sistema y qué no; en consecuencia, la urgente necesidad de presentar los lineamientos de una pedagogía decolonial. Para contrarrestar esta dominación, los maestros y los agentes sociales del currículo han de considerar a la pedagogía como una "configuración conceptual comprensiva"; de aquí que la pedagogía decolonial visibiliza esta concepción al comprender la configuración conceptual de lo "nuestro", de lo "otro", de la génesis del ser hombre como "ser humano".

En Colombia, la construcción de una pedagogía decolonial exige un profundo cambio de mentalidad de los actores sociales del currículo, que asumieran los principios teóricos y prácticos que plantea el reconocimiento de lo nuestro, la interculturalidad crítica, la interculturalidad decolonial y la pedagogía crítica, ya que "no hay práctica social, más política que la práctica educativa; en efecto, la educación puede ocultar la realidad de la dominación y la alienación, o puede, por el contrario, denunciarla, anunciar otros caminos, convirtiéndose en herramienta emancipadora". ${ }^{6}$

\section{Primer lineamiento: el reconocimiento de lo nuestro}

El primer lineamiento de una pedagogía decolonial debe caracterizarse por el reconocimiento de lo nuestro, la diferencia, "lo otro", en que se permita dialogar a los saberes ancestrales con las ciencias y las tecnologías; así, este diálogo de saberes se relaciona con la posibilidad de que diferentes formas culturales de conocimiento puedan convivir en el mismo espacio educativo, ya fuese la universidad o las instituciones educativas; es decir, que puedan acercarse al favorecimiento de la transculturalidad, para entablar diálogos y prácticas articuladoras con los conocimientos y saberes que han sido excluidos de la ruta moderna de las llamadas epistemes, ya que se decía que éstas eran míticas o supersticiosas, conocimientos ligados con poblaciones especialmente de Asia y América Latina, entre otros, que fueron sometidos al dominio colonial europeo; lograr este diálogo de saberes no es una

${ }^{6}$ Catherine Walsh, "Interculturalidad crítica y pedagogía decolonial”, Red de Interculturalidad (2014), 17, https://redinterculturalidad.files.wordpress.com/2014/02/ interculturalidad-crc3adtica-y-pedagogc3ada-decolonial-walsh.pdf

Rev. His. Educ. Colomb-Vol. 24 № 24, enero-junio 2020-San Juan de Pasto-Colombia-ISSN 0123-7756-ISSN (Versión online) 2422-2348-pp. 15-44 
situación fácil, ya que "los conocimientos que vienen ligados a saberes ancestrales o tradiciones culturales lejanas son vistos como doxa, es decir como obstáculo epistemológico que debe ser superado"; 7 de esta manera, se piensa erradamente que solo son legítimos aquellos conocimientos de la academia; es decir, aquellos que cumplen con las características metodológicas y epistémicas impuestas por la colonialidad.

Por lo tanto, en este primer lineamiento del reconocimiento de lo nuestro, el diálogo de saberes solo es posible a través de la decolonización del conocimiento, lo que nos lleva a pensar que, de igual manera, es necesaria la decolonización de la universidad, de las instituciones educativas; es decir, aquellas instituciones productoras o que administran el conocimiento: "Decolonizar el conocimiento significa hacer evidente el lugar desde el cual se produce este conocimiento; es decir, que ya no es el alejamiento, sino el acercamiento, el ideal que debe guiar al investigador de los fenómenos sociales o naturales."

El reconocimiento de lo nuestro significa acercarse a la "doxa", para que así todos los conocimientos y saberes conectados a tradiciones ancestrales empiecen a ganar legitimidad y puedan entenderse como "pares iguales", en un verdadero diálogo de saberes; José Rozo Gauta (2004) refiere:

(...) Es necesario cambiar las ideas y prácticas eurocéntricas, especialmente la imposición colonial de la visión occidental del mundo y de sus prácticas e ideas económicas, sociales, educacionales y cognitivas. (Gauta, 2004, 164)

En este sentido, a través del diálogo de saberes se comprende que es posible refutar una epistemología hegemónica, que solo acepta como válido el conocimiento que se genera en la academia; no se trata de desconocer o negar los avances científicos de la humanidad, sino de reconocer que en las tradiciones ancestrales y en los legados de los saberes de los antepasados y, en general, de lo "otro", lo "diferente", también existe un saber genuino, que necesita ser reconocido. Este diálogo de saberes resignificará los procesos educativos, para permitirle al ser humano reflexionar sobre su estar en el mundo, en relación recíproca con la naturaleza.

7 Santiago Castro-Gómez, "Decolonizar la universidad. La hybris del punto cero y el diálogo de saberes", en El giro decocolonial, eds. Santiago Castro-Gómez y Ramón Grosfoguel (Bogotá: Siglo del hombre/Universidad Central/Pontifica Universidad Javeriana, 2007), 88.

8 Castro-Gómez, "Decolonizar la Universidad", 89. 
El reconocimiento de lo nuestro debe gestarse desde las herencias culturales y los saberes actuales; es decir, bajo una visión de endogénesis, entendida como la capacidad de habitar de forma coherente un territorio geográfico, cultural y ambiental, para aprehenderlo en todas las dimensiones del ser: sentir, actuar, saber y pensar, con un sentido basado en el pensamiento propio, legítimo, auténtico y georeferenciado para la formación innovadora de un ser humano constructor de condiciones favorables para la paz, la equidad social, el desarrollo sostenible, el respeto por la pluralidad, la valoración de la diferencia, la herencia cultural y la responsabilidad democrática, que generan espacios de humanidad pluriétnica y multicultural.

Entonces, el reconocimiento y la reinterpretación de lo nuestro debe generar la producción de un pensamiento propio; como lo plantea Guerrero Vinueza, ${ }^{9}$ este pensamiento propio exige un esfuerzo mental para abandonar los sustentos teóricos construidos en otras latitudes, que silenciaron otras cosmovisiones e instalaron "su" verdad como la única forma de conocer la vida humana, la sociedad, la naturaleza y la cultura. Construir pensamiento propio implica cuestionar radicalmente esa "epistemología imperial”, ciega a las prácticas sociales de otras culturas. La construcción de una Pedagogía Decolonial en el contexto del reconocimiento de lo nuestro debe generar una crítica a los patrones de poder y de saber instaurados por la colonialidad; en cambio, se debe afirmar y fortalecer lo propio, lo nuestro, inspirarnos en la "epistemología del sur" que, como la acentúa Guerrero Vinueza, ${ }^{10}$ es un paradigma social y político-emergente, cuya teoría nos proporciona el sustento histórico y filosófico para la creación de pensamiento propio.

Esta visión de reconocimiento de lo nuestro no solo se refiere a la intención de endogenarse de forma, sobre las creencias ancestrales propias o una versión casi romántica de recuperar la condición del génesis de un territorio, sino debe reconocer la relación biunívoca del hombre con la naturaleza; lo nuestro implica el reconocimiento de otras culturas, con las cuales se debe dialogar. La educación debe ser parte de la cotidianidad y habitualidad de la sociedad situada como un todo, no solo en las aulas de clase, sino como una manifestación íntegra en todos los escenarios y así poder

9 Gerardo León Guerrero Vinueza, Introducción a la descolonización de las Ciencias Sociales y la educación: elementos para la construcción de pensamiento propio (Pasto: UNED, 2016), 73.

${ }^{10}$ Guerrero Vinueza, "Introducción a la Descolonización de las Ciencias Sociales”, 73. 
construir un paradigma emergente de educación decolonial, con la realidad de una epistemología de cada región, de cada territorio; es decir, de lo nuestro, el "pensamiento y la educación propia" ${ }^{11}$ lo cual deberá ser una tarea en continúa construcción. Esta dimensión epistémica requiere un reconocimiento de lo urbano, de la aldea, su ruralidad y localidad; solo así se podrán construir procesos dialógicos de interpretación de las realidades universales y tener en cuenta que el proceso pedagógico-crítico parte de lo que posee cada región para entender y reflexionar sobre los devenires de la globalización.

En contradicción, existe la estandarización de la educación, derivada de la homogeneización de la comunicación y la cultura en la sociedad global, que "se traduce en una tarea mental como un efecto directo de la globalización"; ${ }^{12}$ para contrarrestarlo, se requiere "un bien vivir y un sentirpensar, desde la pedagogía, para que esta signifique y sitúe a los actores educativos en los contextos". ${ }^{13}$ Situarlos significa sentar las bases de una pedagogía decolonial desde lo nuestro, para gozar de un "bien vivir", que respondiera a la espiritualidad de los pueblos con la naturaleza, vivir en hermandad y especialmente en complementariedad, lo que privilegia el diálogo, el consenso; y respondiera a la identidad natural de los interrogantes: “¿quiénes somos, de dónde venimos y para dónde vamos?", la relación estrecha con la tierra y el territorio.

Así se fortalecerán la cultura y la identidad, y esta, a su vez, permitirá la construcción de un currículo autónomo y propio, conducente al diálogo reflexivo con otras culturas para pensar y hacer historia para el porvenir, y crear una necesaria relación crítica entre lo local y lo universal, consciente de las transformaciones, y que se interrogue sobre sus posibilidades, tanto regionales como universales: "Una historicidad crítica que dé cuenta de procesos y no de sucesos, evidenciando los límites de la cultura", ${ }^{14}$ que establezca el necesario diálogo epistémico entre la racionalidad occidental

${ }^{11}$ Sonia del Mar González Bonilla, Cambio social para el desarrollo sostenible. (Cali: Pontificia Universidad Javeriana, 2007), 20.

${ }^{12}$ Jesús Martín Barbero, "Culturas y comunicación globalizada", Revista Científica de Información y Comunicación. No. 6 (2009): 177-189.

${ }^{13}$ Arturo Escobar, "Sentipensar con la tierra: las luchas territoriales y la dimensión ontológica de las epistemologías del sur", Revista de Antropología Iberoamericana, vol. 11. $\mathrm{N}^{\mathrm{o}} 1$ (2016): 17-29.

${ }^{14}$ Nadia Hakim Fernández, "Los límites de la cultura y de las teorías de la identidad: una entrevista a Alejandro Grimson", Revista de Antropología Social. No. 23 (2014): 260268. 
y la racionalidad andina, como un camino para la construcción de pensamiento propio; Guerrero Vinueza lo plantea en su texto Introducción a la descolonización de las Ciencias Sociales y la Educación.

Una pedagogía decolonial, desde este primer lineamiento, el reconocimiento de lo nuestro, trata el imperante e ineludible precepto de generar pensamiento propio, como lo refiere Guerrero Vinueza: ${ }^{15}$ "decolonizarnos es liberarnos, es hacer ejercicio de creación, es emanciparnos y adoptar un pensamiento crítico desde nuestra realidad, es dejar de ser colonizados y crear un lenguaje y pensamiento diferentes, es crear distintas maneras y formas de vivir y de ser". Por lo tanto, un paradigma que nos proporciona conocimientos básicos para la creación de pensamiento propio es la interculturalidad.

\section{Segundo lineamiento: interculturalidad crítica}

El segundo lineamiento trazado para la construcción de una pedagogía decolonial surge a partir de la interculturalidad crítica, entendida como un proyecto epistémico, político, económico, histórico, social, cultural, educativo y ambiental. En este contexto, una pedagogía decolonial es un cambio profundamente estructural. Así, la interculturalidad crítica se evidencia como la dimensión ontológica del respeto por el otro y legitima la alteridad como una herramienta pedagógica que cuestiona los agenciamientos, productos de la racialización, subalternización, inferiorización, subordinación y construcciones de relaciones verticales de poder en los procesos de enseñanza-aprendizaje.

Según Catherine Walsh, ${ }^{16}$ se pueden señalar tres sentidos o perspectivas distintas para el término interculturalidad: relacional, funcional y crítica. La interculturalidad relacional se refiere al contacto o intercambio entre culturas, prácticas, tradiciones o valores, que podrán darse en condiciones de igualdad o desigualdad y oculta o minimiza la conflictividad y los contextos de poder y dominación en los que se lleva a cabo la relación. La interculturalidad funcional es el reconocimiento de la diversidad y diferencia cultural, cuya finalidad es la inclusión al interior de la estructura social establecida; no toca las causas de la asimetría y desigualdad social y cultural.

\footnotetext{
${ }^{15}$ Guerrero Vinueza, "Introducción a la Descolonización de las Ciencias Sociales", 65.

${ }^{16}$ Walsh, "Interculturalidad crítica y pedagogía decolonial".
} 
Este texto se centra en la interculturalidad crítica que, según Walsh, cuestiona profundamente la lógica irracional e instrumental del capitalismo y apunta hacia la construcción de sociedades diferentes al "otro" ordenamiento social; por lo tanto, cuestiona seriamente lo colonial, aviva la voz de los históricamente excluidos, en busca de remover y generar procesos y transformaciones de las estructuras que han legitimado la dominación de unos grupos sobre otros. Para que se posibilitara la interculturalidad crítica se necesita desmontar el papel de la escuela como institución que ha reproducido las formas de poder $\mathrm{y}$, con ellas, los procesos de subalternización de unos grupos respecto a otros. Es necesario pensar en una educación que presente una escuela "otra", en la que se escuchen las voces de los estudiantes y se permitiera el diálogo con los saberes y con los distintos autores que llevan sus conocimientos disciplinares al aula; se requiere una educación de pluralidad, en la que se escuchasen y convergieran múltiples voces, experiencias, saberes para que, a través de lo educativo, se fortalezcan distintas maneras de ser y de habitar el mundo o la aldea planetaria en la que se vive.

Lograrlo implica la acción conjunta de las decisiones administrativas, sociales, económicas y pedagógicas, donde los procesos organizacionales conlleven, con ética, múltiples recursos para propender por entornos protectores y favorables enfocados en las comunidades educativas, pero que, igualmente, permitan la transformación de acciones pedagógicas como la organización temática de los currículos, coherentes con las necesidades actuales de indagar qué quiere saber el estudiante y formar así una amalgama amigable de conocimientos con aquellos saberes universales y ancestrales que el educando quisiera gustosamente conocer. De igual manera, debe generarse una transformación de las didácticas para que innovaran, que cautivaran la mente del "otro"; las formas de evaluación no existirán para la exclusión, sino para la valoración de aquello que entreteje la urdimbre de pensamientos en jóvenes y niños; una interculturalidad crítica que permita reemplazar procesos evaluativos por procesos investigativos para conocer y reconocer al "otro" y generar así un juicio de valor, que les permita crecer, ser reconocidos, poder ser valorados y legitimados en la diferencia, para evitar los rezagos de la colonialidad que en la escuela muchas veces se reviven, como son la exclusión, la marginación y discriminación, entre otras.

Como resultado de esto, se entiende que la interculturalidad crítica, ligada estrechamente con la pedagogía decolonial está por desarrollarse, 
aún es incipiente, por cuanto se debe empezar a desmontar las bases de la colonialidad, explicada por el peruano Aníbal Quijano; ${ }^{17}$ la colonialidad del poder, como aquella que regula las relaciones de trabajo, las de dominación $v s$. explotación, las de género y subjetividad; la colonialidad del ser, proceso en el cual se inferioriza y deshumaniza a determinados grupos poblacionales y se pone en condición de superiores a otros grupos; aquí el discurso del poder desempeña un papel fundamental, porque equivocadamente, a través del discurso educativo, se convence que las diferencias y todo aquello que lo entrañaba eran naturales; y la colonialidad del saber, determinada por ocultar, negar, desconocer, invisibilizar tanto las formas de pensamiento como el desarrollo del conocimiento alcanzados por los grupos que fueron colonizados.

A propósito, Guerrero Vinueza ${ }^{18}$ afirma que "la colonialidad del saber es hegemonía cultural, es imposición de conocimiento, es rechazo a otros saberes, a otras racionalidades, es destrucción de las otras formas de creación de conocimiento"; desde esta mirada, es muy importante repensar el protagonismo del docente para la implementación de la pedagogía decolonial, capaz de romper paradigmas para no repetir teorías o discursos impuestos que desconocen la identidad y, en cambio, generar un pensamiento crítico emancipador y comprometido con la realidad y la transformación del contexto.

La pedagogía decolonial se relaciona entrañablemente con el hecho de entender que existen "otras" formas de ser, de pensar, de comprender y organizar el espacio, el conocimiento, en fin, el mundo; en este sentido, se comprende que la interculturalidad crítica está aún por desarrollarse, porque implica revertir las bases del poder sobre las que está construida la sociedad. Como bien lo afirma Catherine Walsh (2005), en su artículo "Interculturalidad crítica y decolonialidad": "la interculturalidad aún no existe, es algo por construir. Va mucho más allá del respeto, la tolerancia y el reconocimiento de la diversidad; señala y alienta más bien un proceso y proyecto social político dirigido a la construcción de sociedades, relaciones y condiciones de vida nuevas y distintas" $(p, 140)$.

Por lo tanto, el proyecto que plantea Walsh debe generar los saberes "otros" desde las instituciones educativas o aquellas que administran la

${ }^{17}$ Quijano, "Colonialidad del poder, eurocentrismo y América Latina”, 20.

${ }^{18}$ Guerrero Vinueza, "Introducción a la Descolonización de las Ciencias Sociales y la Educación", 65. 
educación; se debe enseñar a establecer relaciones del hombre consigo mismo, con la naturaleza y la vida, que permitiese "sentir" y experimentar emociones que incluyeran también aspectos como la espiritualidad y que se considerase una parte fundamental del ser humano. La interculturalidad crítica debe convertirse en un proyecto alternativo, insurgente, contra la colonialidad del poder, del saber y del ser y, ¿por qué no decirlo?, de la colonialidad de la naturaleza; esta interculturalidad crítica está aún por desarrollarse, pero constituye una utopía que establece las aristas necesarias para lograrlo a través de procesos de ruptura epistémica que produzcan grandes cambios en los cimientos de la sociedad, que trasciendan las limitaciones teóricas de la filosofía intercultural.

Entonces, se trata de comenzar a desmontar las diferentes formas cómo se levantó la colonialidad del poder, del saber y del ser; abrir el pensamiento a otras formas del conocimiento, de relacionarse e iniciar un replanteamiento de paradigmas absurdos que, desde esta instancia, han permeado la educación, para converger en un pensamiento de acción, para transitar el camino de la construcción de una pedagogía decolonial como una urgente acción humana, en un significativo intento de participar en la construcción de una sociedad que legitimase las diferencias, que permitiera conversar con ellas en igualdad y equidad de condiciones.

De la utopía de construir y llevar a la acción una pedagogía decolonial en el marco de la interculturalidad crítica y ante la enormidad de las preguntas de cómo hacerlo, cómo lograr una sociedad menos desigual, menos excluyente, menos marginal, surge la propuesta de la investigadora Catherine Walsh, que se orienta hacia:

(...) una perspectiva crítica de la interculturalidad, la que se encuentra enlazada con una pedagogía y praxis orientadas al cuestionamiento, transformación, intervención, acción y creación de condiciones radicalmente distintas de sociedad, humanidad, conocimiento y vida; es decir, proyectos de interculturalidad, pedagogía y praxis que encaminan a la decolonialidad. ${ }^{19}$

Walsh señala que "es un proyecto que apunta a la re-existencia y a la vida misma, hacia un imaginario "otro" y una agencia "otra" de con-vivencia de vivir "con-" y de sociedad". ${ }^{20}$ Esta perspectiva se articula con la mirada

${ }_{19}$ Walsh, "Interculturalidad crítica y pedagogía decolonial", 80.

${ }^{20}$ Walsh, "Interculturalidad crítica y pedagogía decolonial", 10. 
decolonial y propone una mirada como forma de reevaluar todo aquello que la colonia ha impuesto. En este sentido, refiere Guerrero Vinueza, ${ }^{21}$ es "importante plantear una nueva educación fundamentada en la dimensión intercultural para crear pensamiento propio"; al parecer de Gabriel Kaplún, ${ }^{22}$ "no se trata de producir conocimiento local con teoría ajena - teoría útil, sin duda, pero no única, sino también de construir teoría propia, construyendo lugares epistemológicos fronterizos entre la racionalidad moderna occidental y otras modernidades y racionalidades posibles".

Por lo tanto, esta articulación entre lo intercultural crítico y lo decolonial genera e impulsa la construcción de una pedagogía decolonial, que postula la diferencia desde lo relacional, mucho más distanciado que desde la calidad educativa o encontrar seudo-satisfactores que se ofrecen desde los entes gubernamentales; se requiere una pedagogía decolonial que se pregunte por el verdadero sentido educativo de un mundo caracterizado por profundas diferencias y desigualdades.

Estos son un mundo y una sociedad de grandes retos frente a una profunda incertidumbre que problematiza y, a veces, genera temores de toda índole, pero, igual, exige reaccionar para resurgir. Por lo tanto, una pedagogía decolonial tiene que ir más allá de lo disciplinar en espacios de la escuela misma, una pedagogía que proponga bases epistémicas, acciones didácticas, modos y diferentes prácticas en las que no hubiera unas caducas y únicas formas "válidas" y, como consecuencia, solo unos sujetos validados frente a una gran cantidad de sujetos excluidos; claro, aquellos que no se dejaron homogenizar; acentúa Walsh que "se debe trabajar en pro de una interculturalidad dirigida a enfrentar y transformar los diseños coloniales que han posicionado el conocimiento como saber no moderno y local, al frente de la universalidad y no temporalidad del conocimiento occidental". ${ }^{23}$

Una pedagogía decolonial, en el marco de la interculturalidad crítica, debe establecer acciones dialógicas y debe indagar, cuando se diga que no se puede, por las razones de su imposibilidad, y así generar bisagras y puentes que restablezcan la interacción propia de la humanidad, que

${ }^{21}$ Guerrero Vinueza, "Introducción a la descolonización de las Ciencias Sociales", 73.

${ }^{22}$ Gabriel Kaplún. "Indisciplinar la Universidad", en Pensamiento crítico y matriz (de)colonial. Reflexiones latinoamericanas, ed., Katherine Walsh (Quito: Universidad Andina Simón Bolívar/Abya-Yala, 2005), 60.

${ }^{23}$ Caherine Walsh, "Interculturalidad, conocimientos y decolonialidad", Signos y pensamientos, vol. 24. No. 26 (2005): 39-50. 
permitiera cerrar las brechas entre la academia, los saberes y las acciones que se desarrollan y que los actores que intervienen en el proceso de aula se reconozcan y, aún más, se validen y puedan construir juntos proyectos reales; tal como lo señala Tubino, ${ }^{24}$ una educación que "debe ser diversificada, abierta a las diferencias, flexible a las circunstancias, no homogenizante".

Por lo tanto, la pedagogía decolonial inspirada en la interculturalidad crítica tiene que dar cabida, a través de lo curricular, y trabajar sobre las actitudes de los maestros y los agentes sociales del currículo acerca de las diferencias y los diferentes; el maestro debe transformar su poder en afecto y anular su discurso de "amo y esclavo" frente a todos los grupos poblacionales; el maestro debe alejar totalmente su pensamiento respecto a que el "otro" no puede, para que existiera, de verdad, una relación horizontal; totalmente ligado a esto, debe existir la decolonización de los discursos y los mensajes que desde allí emergen; esto atañe al trabajo pedagógico con los medios de comunicación y masas, ya que mucho de lo que se cree sobre los otros se construye desde estos medios. Entonces, es urgente que las Instituciones Educativas se ocupasen del análisis contextualizado y semiótico de estos mensajes como parte de las propuestas curriculares.

\section{Tercer lineamiento: pedagogía crítica}

Para seguir esta ruta esperanzadora de trazar los lineamientos que contribuyeran a la construcción de una pedagogía decolonial, se necesita plantear el tercer lineamiento: la Pedagogía Crítica, como un campo donde se gestasen nuevas prácticas pedagógicas, de autorreflexión teórica por parte del maestro, de movilización política y de expresiones de resistencia. Desde esta óptica, la acción de una pedagogía decolonial se propone, como lo sugieren Bárcena y Melich, ${ }^{25}$ en el sentido de una relación de alteridad; es decir, de una relación con el otro que, ante todo, tiene que ser una relación ética, basada en la acogida, el afecto y la responsabilidad respecto al "otro"; en este marco de enunciación, se propone desplegar las posibilidades de la pedagogía crítica; por lo tanto, se reconoce la pedagogía decolonial como aquella pedagogía que legitima la alteridad y tiene su sustento en la pedagogía crítica.

\footnotetext{
${ }^{24}$ Fidel Tubino, “Interculturalidad para todos: ¿un eslogan más?”, Palestra, 1-6, http:// repositorio.pucp.edu.pe/ index/handle/123456789/11898

${ }^{25}$ Fernando Bárcena y Joan-Carles Mèlich, La educación como acontecimiento ético. $\mathrm{Na}$ talidad, narración y hospitalidad (Barcelona: Paidós, 2000).
} 
Se debe considerar que, en Colombia, se reconocen varias configuraciones de la pedagogía crítica; por ejemplo, la presencia de pedagogías feministas, educaciones propias, pedagogía de la alteridad y, claro está, la pedagogía decolonial, que es una construcción ética, con la potencialidad hermenéutica de transformación y resistencia, una educación con el propósito de hacerse cargo de un "otro"; ese otro es el estudiante en condiciones de vulnerabilidad, exclusión y desigualdad; de aquí que una pedagogía decolonial, con fundamento en la pedagogía crítica, fuese una pedagogía de la alteridad.

Estos escenarios de desigualdad y exclusión se ven claramente reflejados en las comunidades cifradas por la ruralidad y acotadas como zonas marginales, donde no se reconocen las diferencias y las violencias se naturalizan como improntas culturales; allí, los directivos y docentes deben afrontar estas marcas sociales, equipados con pedagogías críticas, que permitieran reflexionar sobre las realidades que enfrentan los estudiantes para generar conciencias transformadoras, que contrarrestasen las marcas hegemónicas de la modernidad; tal como lo refiere Vega:

"Fortaleciendo los dispositivos de control y deshumanización del homo faber, ejerciendo sobre él violencias simbólicas y físicas, ahondando las desigualdades económicas, sociales y culturales, resignificando y actualizando el papel del colonizador y el colonizado". ${ }^{26}$

Ante este escenario propio de la colonialidad, la labor consecuente del pedagogo es ser un transformador, capaz de esclarecer y desenmascarar las prácticas de dominación; para llevar a cabo este alumbramiento humanizado, se requiere de epistemologías, didácticas y pedagogías críticas, "caracterizadas por la dialogicidad, la otredad, la criticidad como procesos deconstructivos de las realidades". ${ }^{27}$

En consecuencia, la pedagogía crítica debe ser una práctica democrática, pertinente, sensible al contexto y políticamente transformadora; la pedagogía crítica, en el marco de la pedagogía decolonial, se inscribe en un proceso reflexivo y en una práctica del compromiso; es una política de vida

${ }^{26}$ Guillermo Vega. "El concepto de dispositivo en M. Foucault: su relación con la microfísica y el tratamiento de la multiplicidad". Revista Digital de Filosofía. No. 6 (2017): 67-89.

${ }^{27}$ Gabriela López. "Docencia e Investigación”, Pensamiento crítico en el aula, vol. 37. No. 22 (2013): 42-56. 
en colectivo que se ocupa de los cuidados recíprocos y solidarios, donde cuidar es otra forma de constituir comunidad, es hacerse responsable de un "otro" y esta responsabilidad genera prácticas de solidaridad en torno a proyectos pedagógicos, sociales, políticos, culturales y ambientales. Desde esta perspectiva, una configuración de la pedagogía crítica es la pedagogía decolonial por el acompañamiento que entraña el requerimiento de "cuidar al otro", de regalarse su acogida, su reconocimiento, de recibirlo en el fulgor de sus diferencias y de afrontar la sensibilidad de la ternura y el tiempo sereno y calmado para la disposición de escuchar el relato de la historia del "otro", de la historia que necesita intervenirse para su emancipación; desde esta pedagogía, entendemos que formar es seducir al "otro" y educar es viajar junto al "otro", para indicarle los saberes de la cultura para su próxima parada, en la cual bajará solo.

En este contexto, la pedagogía crítica se sostiene en la propuesta de Paulo Freire, ${ }^{28}$ pedagogía del oprimido, pedagogía de la autonomía, de la esperanza y de la indignación; en fin, una pedagogía decolonial, pedagogías de y para el reconocimiento, la pregunta, el diálogo, pedagogía de la otredad, pedagogía de y para la resistencia y la emancipación, para la reinvención, para la re-existencia, pedagogía que desacomoda, que investiga, que remueve, que desestabiliza, pero, ante todo, alienta; es decir, la pedagogía decolonial que desafía los discursos desgastados y las prácticas hegemónicas desde cada escenario donde el maestro y el directivo actúan y que demanda un posicionamiento ético y político. Toman fuerza los postulados freireanos sobre una pedagogía decolonial, puesto que estos lineamientos epistémicos se inscriben plenamente en el paradigma críticosocial, que vitaliza el reconocimiento del "otro y los otros"; esta acción pedagógica alcanza su real importancia ya que, en su praxis, no se pretende tomar superficialmente la diferencia colonial como objeto de estudio; su objetivo y su horizonte práctico se basan en la transformación política del hombre a partir de la educación y el ejercicio pedagógico consciente, donde la inclusión social fuese uno de los pilares fundamentales para el fortalecimiento del saber y la educación como un factor multiplicador de conocimiento.

Por esta razón, la pedagogía freireana surge desde "el rumor de los desheredados de la modernidad, aquellos para quienes sus experiencias y

${ }^{28}$ Paulo Freire, Pedagogía del oprimido (Buenos Aires: Siglo XXI, 2002), 20. 
sus memorias corresponden a la otra mitad de la modernidad, esto es la colonialidad". ${ }^{29}$

Al retomar al pensador brasileño Freire, la educación liberadora es un acto político y una apuesta pedagógica, mediada por los horizontes ético y crítico, pensados desde la exterioridad, que evidencia que la pedagogía del oprimido, de Freire, ${ }^{30}$ tiene diversos momentos, como la estructura de la dominación, las formas de ser y de comportarse de los oprimidos. En tanto, se refleja claramente que la resistencia hacia la colonización no es suficiente para recorrer el camino de la liberación, porque no se toma conciencia del proceso de colonización del poder, del saber y del ser; se muestra temor a la libertad y se prefiere seguir siendo oprimido.

Por este motivo, se propone una pedagogía decolonial que asumiera su lugar en el mundo, lo cual implica un acto de madurez política, mayoría de edad en el tránsito de un camino por descubrir; durante ese recorrido es pertinente reconocerse como parte de una cultura e innumerables tradiciones y, ahí, en el lugar de la "enunciación, se lucha por la liberación simbólica, epistémica y económica". ${ }^{31}$

De esta manera, dentro del aula de clase se necesita reflexionar sobre las nocivas relaciones de poder, como exigencia ética requerida para no seguir reproduciendo la lógica binaria del oprimido y el opresor, del amo y esclavo, prácticas insertadas en la cotidianidad y vinculadas a las interrelaciones sociales y culturales, una cultura y un pensamiento sujeto a las lógicas de dominación colonial. Por consiguiente, para llevar a cabo una transformación profunda, se precisa una educación liberadora, que conduzca hacia una praxis decolonizadora inspirada por una ética de responsabilidad y generosidad humana; una pedagogía decolonial que posibilite caminar hacia la transformación de los esquemas sociales imperantes, como lo soñó Freire; una pedagogía que avance hacia el reconocimiento, hacia el diálogo horizontal, la equidad y que abandone la historia de exclusión, marginalidad, violencia y olvido.

La realidad excluyente de nuestra sociedad proporciona las hermenéuticas de la decolonización, que permiten proyectar nuevos porvenires del ser, el bien vivir y el saber, en busca de horizontes críticos en el devenir de las pedagogías vitales que permitan "dialogar las diferencias

\footnotetext{
${ }^{29}$ Freire, "Pedagogía del oprimido", 20.

${ }^{30}$ Freire, "Pedagogía del oprimido", 20.

${ }^{31}$ Walter Mignolo, La idea de América Latina (Barcelona: Gedisa, 2007).
} 
en un marco de legitimidad, dignidad, igualdad, equidad, respeto y solidaridad, que alienten los tejidos educativos al repensar al "otro", como el próximo, el ser que está y vive entre el cruce de las fronteras". ${ }^{32}$ Según Fleuri (2006)

No se trata (...) de reducir al otro a lo que nosotros pensamos o queremos de él, no se trata de asimilarlo a nosotros mismos excluyendo su diferencia, se trata de abrir la mirada al extrañamiento, al dislocamiento de lo conocido para lo desconocido, que no es solo el otro sujeto con quien interactuamos socialmente sino también el otro que habita en nosotros mismos. ${ }^{33}$

Así mismo, la toma de conciencia que pasa de una conciencia sometida a una conciencia crítica se puede lograr con acciones sencillas; así, "ante la cultura del silencio, la dignidad habla; ante el racismo, el cara a cara se niega y mitifica la racionalidad", ${ }^{34}$ donde la desmitificación reconoce y significa la cultura propia, que exalta los saberes y haceres ancestrales, genuinos y legítimos conocedores de nuestra historia.

Ante la deshumanización, la humanización se convierte en la prueba fehaciente de que el ser humano es el único que tiene la capacidad de humanizarse a través del reconocimiento del otro, acción que se aborda al ser solidarios y recíprocos, tejer porvenires a partir del diálogo liberador y constructor de amor y esperanza, una pedagogía decolonial reivindicadora que:

Fortalece un ser reinventado políticamente, un hombre nuevo en continua transformación de sus prácticas existenciales, el cual replantea críticamente el mundo teniendo como horizonte y como expectativa una hermenéutica continua y una vida decolonial. ${ }^{35}$

Estos lineamientos de la pedagogía decolonial deben dinamizarse a partir de una perspectiva deconstructiva, entendida esta dimensión epistémica como un proceso crítico, un desaprender, un desedimentar,

\footnotetext{
${ }^{32}$ Walsh, "Interculturalidad crítica y pedagogía decolonial", 60.

${ }^{33}$ Reinaldo Fleuri, "Intercultura y Educación”. Revista Astrolabio. No. 1 (2006): 8, http: // www.astrolabio.unt.edu.ar/articulos/multiculturalismo/articulos/fleuri.php

${ }^{34}$ Walter Mignolo, "Un paradigma otro: colonialidad global, pensamiento fronterizo y cosmopolitismo crítico". Dispositivo, vol. 25. No. 52 (2005): 127-146.

${ }^{35}$ Chela Sandoval, Metodología de los oprimidos (Minneapolis/Londres: University of Minnesota Press, 2000), 55.
} 
un deshacer para volver a hacer, pero que mantiene lo multidimensional del pensamiento decolonial; es decir, deconstruir la binariedad del pensamiento hegemónico, una deconstrucción que implica necesariamente el reconocimiento del otro, interpretado a partir de una perspectiva subalterna, analizada desde afuera, para lograr una decolonización intelectual. Al parecer de Guerrero Vinueza, "la deconstrucción consiste en un deshacer sin destruir, un sistema de pensamiento que se nos revela como único, hegemónico o dominante"; la deconstrucción implica poner en sospecha el conocimiento, supone deshacer el discurso cognitivo occidental, poblado de binarismos, de dicotomía, de errores excluyentes, de racismos y racialidad.

\section{Algunas propuestas emergentes de pedagogía decolonial en Colombia}

Es necesario advertir que, en los actuales contextos de hegemonía de pensamiento, de capitalismo cognitivo, fragmentación del vínculo social y de dominación, que fácilmente pueden conducirnos a la desesperanza, se construyen contrariamente en América Latina, y especialmente en Colombia, avances investigativos educativos que le apuestan a la pedagogía decolonial. Cabe anotar que estas propuestas emergentes de la pedagogía decolonial se han investigado de una forma diferente a como se realiza la investigación tradicional, ya que existe urgencia de decolonizar la metodología de la investigación social, humana y educativa; se refiere a las metodologías decoloniales, que atienden en especial a la decolonialidad epistémica, epistemológica y metodológica. Para decolonizar las prácticas investigativas, es necesario situar la investigación en un contexto cultural más amplio y establecer la autocrítica desde el mismo proceso de la investigación, para reconocer al otro sujeto participante como el "otro - yo", en un diálogo efectivamente entre iguales y reflexionar desde una perspectiva holística e integradora: "decolonizar la investigación implica no solo investigar metodologías "otras", sino también cuestionar el contenido de dicha noción y cuestionar incluso el propio término". ${ }^{37}$

\footnotetext{
${ }^{36}$ GuerreroVinueza, "Introducción a la descolonización de las Ciencias Sociales", 65.

${ }^{37}$ Alexander Ortiz Ocaña, María Isabel Arias López y Zaira Pedrozo Conedo, "Metodología 'otra' en la investigación social, humana y educativa. El hacer decolonial como proceso decolonizante", Faia, vol. 7. No. 30 (2018): 172-200.
} 
Una experiencia relevante en el marco de la pedagogía decolonial, desarrollada en Colombia, es la investigación: "Pedagogía decolonial y educación comunitaria; una posibilidad ético política"; esta experiencia se basa en las prácticas de formación en la educación comunitaria (ECO), que se dan contemporáneamente y se encuentra articulada en tres etapas: acercamientos históricos dados entre la ECO y la pedagogía en contextos universitarios; formación ético política en las prácticas de la ECO, que constituye una crítica a la epistemología del saber como poder y la pedagogía decolonial; la tercera etapa la constituye una crítica al discurso pedagógico moderno. Esta pedagogía decolonial, aplicada en Colombia, constituye una urdimbre de preguntas, entre las cuales se cuestionan las prácticas formativas de la ECO; entre ellas se indaga cómo se da la producción de conocimiento en dichas prácticas de formación y desde dónde se legitima ese conocimiento. Esta pedagogía decolonial de la ECO, como práctica emergente de educación comunitaria, visibiliza el hecho de establecer y problematizar sus relaciones con la pedagogía, además de la perspectiva de la ECO, que indaga por la pedagogía del trabajo comunitario, asumido desde las prácticas comunitarias de las universidades, en sus procesos de extensión. De esta manera, se evidencia que existen prácticas de la pedagogía decolonial como una posibilidad crítica al discurso pedagógico moderno.

Otras experiencias de investigación en pedagogía decolonial las presenta el grupo CRECED (Comunidad de reflexión sobre colonialidad y experiencias decoloniales); entre ellas se cita un estudio sobre la emergencia de un currículo decolonial en/desde el sur; esta investigación estudia la caracterización de las prácticas curriculares que producen una educación colonizadora en las organizaciones educativas. Así mismo, este grupo investigativo trabaja el tema del feminismo alternativo y desarrolla su investigación al centrarse en un grupo de personas con una forma "otra" de sentir, conocer, pensar, aprender, ser y vivir. También, se realiza el estudio de la decolonialidad, en el contexto afrocolombiano y en las obras de Gabriel García Márquez y José Martí Pérez.

De igual manera, existe la propuesta emergente: Altersofia y hacer decolonial; "epistemología otra", formas "otras", de conocer y amar; a través de este estudio, se propone "configurar una filosofía que se concentran en la relación sujeto-sujeto; es decir, entre un yo con otro yo, reconocer y visibilizar el saber del otro colonizado y que subalterniza sus 
conocimientos situados (sofías), para emerger así la Altersofia como una epistemología otra, una forma "otra" de conocer y amar"; ${ }^{38}$ se cuestiona así la forma de investigar tradicional y, ante todo, su metodología considera que investigar es escudriñar, buscar con base en buenas y curiosas preguntas, para concluir que "el mediador decolonial configura cultura propia, no investiga, visibiliza", ${ }^{39}$ para la configuración de un pensamiento alterativo.

Estas investigaciones, como propuestas decoloniales, muestran el despliegue del hacer decolonial, la práctica liberadora, emancipatoria y decolonizadora, todas ellas en el camino hacia una consolidación, en la urgencia de la construcción de una pedagogía decolonial.

\section{Conclusiones}

"Decolonizar, refiere, asumir una postura autónoma, insurgente, hacer intervención, incidir y transgredir, señalar y configurar actitudes y estilos alternativos que permitan visibilizar lugares de vivir, de "ser" de reconocer al otro"; ${ }^{40}$ por lo tanto, la pedagogía decolonial debe ser un proyecto que recobrase la conciencia de transformar "con base en lo nuestro" y tiene que ser un proceso gradual, ya que "decolonizar significa ir disminuyendo lo colonial, atenuar, mitigar, no es un resultado, sino un proceso, no es un fin sino un medio para alcanzar el fin"41. Decolonizar significa contrarrestar los efectos de la modernidad que irrumpió en América y tiene su punto de origen en la conquista, que ha dejado consigo un legado colonial, que genera exclusión y marginación, establece un orden jerárquico, que sitúa al europeo como la cúspide del ser, saber y poder, para quedar así al descubierto la colonialidad como la cara oculta de la modernidad.

"La interculturalidad y la decolonialidad son complementarios; no hay interculturalidad plena sin decolonialidad y no hay decolonialidad sin interculturalidad plena. Son dos caras de la misma moneda; a partir del reconocimiento de esta relación se propone la noción de interculturalidad

\footnotetext{
${ }^{38}$ Alexander Ortiz Ocaña, “Altersofía y Hacer decolonial: epistemología 'otra' y formas 'otras' de conocer y amar”, Utopía y Praxis Latinoamericana, vol. 24, No. 85 (2019), 2. ${ }^{39}$ Ortiz Ocaña, "Altersofía y Hacer decolonial”, 28.

${ }^{40}$ Alexander Ortiz Ocaña, María Isabel Arias López y Zaira Pedrozo Conedo, Decolonialidad de la educación: emergencia/urgencia de una pedagogía decolonial (Santa Marta: Editorial Unimagdalena, 2018), 41.

${ }^{41}$ Ortiz Ocaña, Arias López y Pedrozo Conedo, "Decolonialidad de la educación", 44.
} 
decolonial". ${ }^{42}$ La interculturalidad crítica, al igual que la interculturalidad decolonial y sus resultados: las pedagogías decoloniales emergentes, deben convertirse en un proyecto alternativo e insurgente contra la colonialidad del poder, del saber y del ser, a través de procesos de ruptura epistémica que produzcan un pensamiento decolonial, visibilizado en cambios reflejados en los cimientos de la sociedad, que trasciendan las limitaciones teóricas de la filosofía intercultural.

En la pedagogía decolonial, la decolonizacion del saber y del conocimiento no infiere ir en contra de las ciencias modernas o de intentar negarlas o de promover un tipo de "oscurantismo epistémico", sino estas ciencias modernas tienen que ser "rebasadas por algo mejor"; es decir, tienen que ser una ampliación de campo de visibilidad abierto por la ciencia occidental moderna, dado que fue incapaz de abrirse a las emociones, la capacidad de sentir, de rescatar el sentido común, los conocimientos ancestrales y la corporalidad: "No es entonces la disyunción, sino la conjunción epistémica lo que se quiere lograr, un pensamiento integrativo en el que la ciencia occidental pueda enlazarse con otras formas de producción de conocimiento". 43

De esta forma, la intención de la pedagogía decolonial, enmarcada en estos tres lineamientos: el reconocimiento de lo nuestro; la interculturalidad crítica y la pedagogía crítica, se anima y puede garantizarse cuando el maestro utiliza su autonomía en el aula: cuando el maestro cierra la puerta del salón de clase, abre un mundo de posibilidades, de libertades para sus estudiantes con su palabra transformadora y su actuar dialógico de reconocimiento del "otro" que tiene a su lado y ese "otro" es real.

La autonomía le posibilita al maestro proponer, proyectar, soñar con otros "mundos" posibles, con formas metodológicas y didácticas "otras"; aún a expensas de currículos fijos, en el aula, como recinto de libertad y construcción de pensamiento crítico, surgen las acciones dialógicas y se pueden proponer "otras" formas de relación y ayuda entre unos y otros para generar un verdadero diálogo de saberes, que solo es posible a través de la decolonización del conocimiento; esto lleva a pensar que, de igual manera, es necesaria la decolonización de la universidad, de las instituciones educativas; decolonizar el conocimiento significa evidenciar

\footnotetext{
${ }^{42}$ Ortiz Ocaña, Arias López y Pedrozo Conedo, "Decolonialidad de la educación”, 66.

${ }^{43}$ Castro-Gómez, "Decolonizar la universidad", 90.
} 
el lugar desde el cual se produce, para que así todos los conocimientos y saberes conectados a tradiciones o legados ancestrales empiecen a ganar legitimidad y puedan entenderse como "pares iguales".

Así se han trazado los lineamientos que contribuyen a la construcción de una pedagogía decolonial; al empezar por el reconocimiento y la valoración de lo nuestro, la interculturalidad crítica y la pedagogía crítica, estos tres lineamientos conforman una urdimbre y una trama que generan el tejido social de la pedagogía decolonial, cuya importancia radica en la necesidad de formar personas capaces de actuar y pensar críticamente, para asumir un papel protagónico dentro de la historia de nuestras naciones latinoamericanas.

Es claro que estos tres lineamientos no podrán transformar totalmente la educación y/o la escuela como institución; son muchos más los elementos que deberán entrar a vincularse para construir una escuela y un proceso educativo que, más allá de reconocer y validar la diferencia, debe ser una escuela con propuestas pedagógicas concretas, en la cual "las diferencias" fuesen el impulso real para la adecuación y transformación de los discursos, las metodologías y las formas de interacción entre los sujetos, para que los currículos fueran realmente genuinos, socialmente legítimos y culturalmente coherentes y así se pudiera avanzar en la construcción de una sociedad menos desigual y mucho más participativa. Los tres lineamientos que aquí se señalan, para la construcción de una pedagogía decolonial, son puntos de inflexión muy importantes y significativos.

La trilogía de los lineamientos planteados constituye un pensamiento decolonial, entendido como un proceso de resistencia e insurgencia, a las que Walsh denomina acciones pedagógicas y generan la pedagogía decolonial, para promover así prácticas de resistir, re-existir, y re-vivir, ${ }^{44}$ que visibilicen la geopolítica del saber, la teleología identitaria-existencial de la diferencia colonial y la topología del ser, ${ }^{45}$ pedagogía decolonial que configura el análisis crítico, el cuestionamiento, la acción social transformadora y la intervención humana en los campos del poder, del saber, del ser y vivir. Una pedagogía decolonial, propia de auto determinación y auto liberación,

${ }^{44}$ Catherine Walsh, Pedagogía y la lucha por la voz: problemas de lenguaje, poder y educación para los puertorriqueños (Chicago: Universidad de Chicago, 2007), 65.

${ }^{45}$ Nelson Maldonado Torres, Sobre la colonialidad del ser (Bogotá: Lesco/Siglo del Hombre, 2007), 55. 
tal como lo diría Villa Amaya:46 "la escuela no puede continuar siendo un espacio de colonización mental", sino un lugar para la creación de conocimiento emancipador.

Es muy importante concluir que es necesario aportar a la construcción de una pedagogía decolonial, desde las investigaciones precedentes, que ya han abordado la interculturalidad decolonial y sus resultados, como lo son las pedagogías decoloniales; así, existen avances investigativos muy significativos en Latinoamérica y en Colombia, sobre pedagogías decoloniales. Estas propuestas emergentes de la pedagogía decolonial se han investigado a través de las metodologías decoloniales, que atienden en especial a la decolonialidad epistémica, epistemológica y metodológica. Cuando se dialoga efectivamente entre iguales y reflexiona desde una perspectiva holística e integradora, se conforman comunidades de reflexión sobre colonialidad y experiencias decoloniales, que logran la configuración de un pensamiento alterativo. De esta forma, se evidencia el aporte a la construcción de una pedagogía decolonial desde estas investigaciones precedentes.

Estas dimensiones fomentan y revitalizan racionalidades ético políticas, que se alejan del pensamiento hegemónico del mundo occidental colonial; la propuesta de una pedagogía decolonial debe surgir a partir de la herencia cultural, ya que la pedagogía decolonial, en palabras de Walter Mignolo, es un punto de resistencia capaz de resignificar y transformar las formas hegemónicas de conocimiento y poder así construir una verdadera "pedagogía decolonial mediada como una urgente acción humana".

\section{Referencias}

Aquileana. Gilles Deleuze: “Agenciamiento colectivo y Rizomas". 2 de diciembre de 2011. https://aquileana.word press.com/2011/12/02/gilles-deleuzeagenciamiento-colectivo-y-rizomas/ (último acceso: 10 de agosto de 2018).

Castro-Gómez, Santiago. "Historia de la gubernamentalidad: razón de estado, liberalismo y neoliberalismo en Michel Foucault". Ideas y Valores. Vol. 61. No. 150, (2010): 187-215.

${ }^{46}$ Wilmer Villa Amaya. Diversidad, interculturalidad y construcción de ciudad (Bogotá: Universidad Pedagógica Nacional, 2008). 
Castro-Gómez, Santiago. "Decolonizar la universidad. La hybris del punto cero y el diálogo de saberes”. En El giro decocolonial, eds. Castro-Gómez, Santiago y Grosfoguel, Ramón. Bogotá: Siglo del hombre/Universidad Central/Pontifica Universidad Javeriana, 2007.

Deleuze, Gilles. Différence et répétition. París: PUF, 1997.

Dussel, Enrique. Europa, modernidad y eurocentrismo. Santo Domingo: Clacso, 1993).

Escobar, Arturo. "Sentipensar con la tierra: las luchas territoriales y la dimensión ontológica de las epistemologías del sur". Revista de Antropología Iberoamericana. Vol. 11. No. 1, (2016): 17-29.

Foucault, Michel. “L’Histoire de la sexualité”. Projections. No. 6, (2013).

Freire, Paulo. Pedagogía del oprimido. Buenos Aires: Siglo XXI, 2002.

Fleuri, Reinaldo, “Intercultura y Educación”. Revista Astrolabio. No. 1 (2006): 20, http: //www.astrolabio.unt.edu.ar/articulos/multiculturalismo/articulos/ fleuri.php

Gauta, José Rozo, Sistémica y pensamiento complejo. Vol. II. Sistémica, educación y transdisciplinariedad. Medellín: Biogénesis, 2004.

González Bonilla, Sonia del Mar. Cambio social para el desarrollo sostenible. Cali: Pontificia Universidad Javeriana, 2007.

Hakim Fernández, Nadia. "Los límites de la cultura y de las teorías de la identidad: una entrevista a Alejandro Grimson". Revista de Antropología Social. No. 23, (2014): 260-268.

Hernández Sampieri, Roberto; Fernández Collado, Carlos y Baptista Lucio, Pilar. Metodología de la Investigación. México: McGraw-Hill, 2014.

López, Gabriela. “Docencia e Investigación". Pensamiento crítico en el aula. Vol. 37. No. 22, (2013): 42-56.

Maldonado Torres, Nelson. Sobre la colonialidad del ser. Bogotá D.C.: Lesco Siglo del Hombre, 2007. 
Martín Barbero, Jesús. “Culturas y comunicación globalizada”. Revista Científica de Información y Comunicación. No. 6, (2009): 177-189.

Mignolo, Walter. La idea de América Latina. 3ª edición. Barcelona: Gedisa, 2007.

Mignolo, Walter. "Un paradigma otro: colonialidad global, pensamiento fronterizo y cosmopolitismo crítico". Dispositivo. Vol. 25. No. 52, (2005): 127-146.

Miller, Peter y Rose, Nikolas. "Political power beyond the state: problematics of government”. British Journal of Sociology. Vol. 43. No. 2, (1992): 183-193.

Ortiz Ocaña, Alexander. “Configuración epistémica de la pedagogía. Tendencias que han proliferado en la historia de la educación”, Revista de Historia de la Educación Latinoamericana, vol. 19, No. 29 (2017): 165-195.

Ortiz Ocaña, Alexander. “Altersofía y Hacer Decolonial: epistemología 'otra' y formas 'otras' de conocer y amar”. Utopía y Praxis Latinoamericana. Vol. 24. No. 85, (2019).

Ortiz Ocaña, Alexander; Arias López, María Isabel y Pedrozo Conedo, Zaira. "Metodología 'otra' en la investigación social, humana y educativa. El hacer decolonial como proceso decolonizante”. Faia. Vol. 7. No. 30, (2018): 172-200.

Ortiz Ocaña, Alexander; Arias López, María Isabel y Pedrozo Conedo, Zaira. Decolonialidad de la educación: emergencia/urgencia de una pedagogía decolonial. Santa Marta: Editorial Unimagdalena, 2018.

Quijano, Aníbal. Colonialidad del poder, eurocentrismo y América Latina. Bogotá: Nueva América, 2008.

Sabogal Tamayo, Julián. El desarrollo humano multidimensional. Bogotá: Plaza \& Janés, 2008.

Sandoval, Chela. Metodología de los oprimidos. Minneapolis/Londres: University of Minnesota Press, 2000.

Vega, Guillermo. "El concepto de dispositivo en M. Foucault: su relación con la microfísica y el tratamiento de la multiplicidad". Revista Digital de Filosofía. No. 6, (2017): 67-89. 
Walsh, Catherine. Interculturalidad crítica y pedagogía decolonial. Bogotá: Norma, 2014.

Walsh, Catherine. Pedagogía y la lucha por la voz: problemas de lenguaje, poder y educación para los puertorriqueños. $2^{\mathrm{a}}$ ed. Chicago: Universidad de Chicago, 2007.

\section{Citar este artículo}

Bustos Erazo, Rosa Cecilia. "Construcción de una pedagogía decolonial ...una urgente acción humana". Revista Historia de la Educación Colombiana. Vol. 24 No 24 (2020): 15-44

DOI: https://doi.org/10.22267/rhec.202424.71 